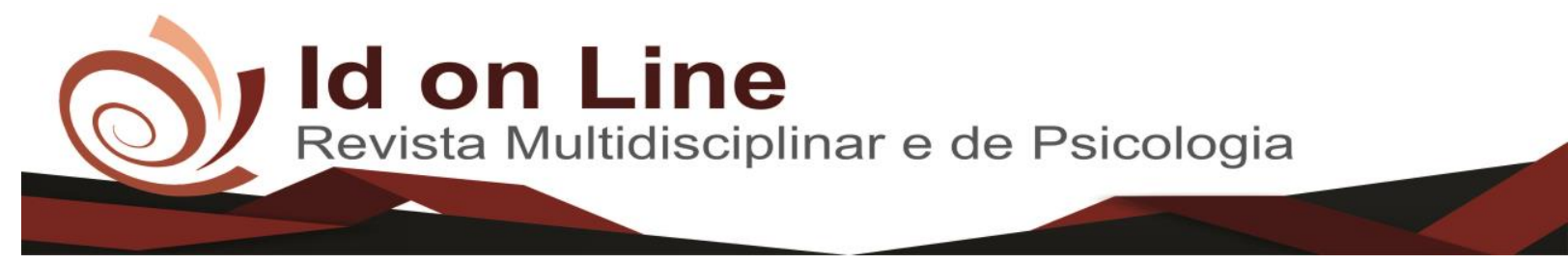

Artigo

\title{
Análise do Nível de Serviço Logístico nas Entregas \\ de Mercadorias em uma Empresa de Bebidas na Cidade de Juazeiro do Norte-CE
}

\author{
Vicente Jacó Alves da Silva ${ }^{1}$; Alyne Leite de Oliveira ${ }^{2}$
}

\begin{abstract}
Resumo: A logística pode ser definida como o processo do planejamento, implementação e o eficiente controle do fluxo de estoque, armazenagem e entrega de mercadorias (BALLOU, 2010). Com um mercado cada vez mais competitivo, as empresas buscam um diferencial no que diz respeito ao Nível de Serviço Logístico prestado, buscando atender e cumprir a missão da logística que é dispor da mercadoria no lugar certo, no tempo certo e nas condições desejadas. Dessa forma, o presente trabalho tem como objetivo analisar o nível de serviço logístico na entrega de mercadorias em uma empresa de bebidas na cidade de Juazeiro do Norte - CE. A coleta de dados foi dividida em duas etapas: Inicialmente realizou-se uma entrevista com o gestor do setor de logística da organização em estudo, em seguida foi aplicado um questionário com 32 distribuidores que atuam na cidade de Juazeiro do Norte-CE, utilizando-se o critério de acessibilidade. A partir dos resultados obtidos pode-se perceber que $69 \%$ dos entrevistados são clientes fidelizados que compram mais de uma vez por mês; a pesquisa mostra também que $91 \%$ dos distribuidores afirmam que a mesma consegue entregar todos os produtos com qualidade sem nenhum dano, e que preza pelo cumprimento dos prazos determinados. Endeavor Brasil (2015) destaca que esse é um dos indicadores mais observados pelos clientes. Desse modo, a realização da pesquisa favoreceu não apenas o conhecimento acerca da importância do delineamento do NSL a ser oferecido, como também que indicadores são mais utilizados e percebidos pelos consumidores, o que permite o reconhecimento dessas no tocante a excelência no mercado.
\end{abstract}

Palavras-Chave: Nível de Serviço Logístico. Indicadores de Desempenho. Empresa de Bebidas.

\section{Analysis of the Level of Logistic Service in the Deliveries of Goods in a Company of Beverages in the City of Juazeiro do Norte, State of Ceará}

\begin{abstract}
The logistics can be defined as the planning, implementation and effective control of inventory flow, storage and delivery of goods (BALLOU, 2010). With an increasingly competitive market, companies seek a differential with regard to the logistics service level provided, seeking to meet and fulfill the mission of logistics that is to have the goods in the right place, at the right time and in the desired conditions. Thus, this study aims to analyze the level of logistics service in the delivery of goods in a beverage company in city of Juazeiro do Norte - CE. Data collection was divided into two stages: Initially held an interview with the manager of the logistics sector from the organization in study, then was applied a questionnaire with 32 distributors operating in the city of Juazeiro do Norte-CE, using the criterion of accessibility. From the results obtained it can be seen that $69 \%$ of respondents are loyal customers who buy more than once a month; the survey also show that $91 \%$ of distributors claim that it can deliver all products with quality without any damage, and that values the fulfillment of certain terms (91\% of respondents). Endeavor Brazil (2015) points out that this is one of the most observed indicators by customers. Thus, the research favors not only the knowledge about the importance of design about the NSL to be offered, but also that indicators are most used and perceived by consumers, which allows the recognition of these with regard to excellence in the market.
\end{abstract}

Keywords: Logistics Service Level. Performance Indicators. Beverage Company.

\footnotetext{
${ }^{1}$ Graduando do curso de administração do Centro Universitário Doutor Leão Sampaio/UNILEÃO-jaco-saxofonista@hotmail.com ${ }^{2}$ Professora Orientadora do Centro Universitário Doutor Leão Sampaio/UNILEÃO, especialista em Logística Empresarialalyneoliveira@leaosampaio.edu.br
}

761 Id on Line Rev. Mult. Psic. V.13, N. 43, p. 761-783, 2019 - ISSN 1981-1179

Edição eletrônica em http://idonline.emnuvens.com.br/id 


\section{Introdução}

Dado o crescimento do mercado, avanços da tecnologia e clientes cada vez mais exigentes a logística precisa utilizar ferramentas de integração que gerenciem toda cadeia de suprimentos com eficiência procurando cumprir a missão de tornar disponíveis os produtos ou serviços corretos, no tempo certo, no local certo e nas condições adequadas aos clientes. No entanto, esses fatores não devem ser feitos sem o devido planejamento. Métricas e indicadores de desempenho são fatores fundamentais não só para sustentabilidade empresarial, como também manutenção da percepção de satisfação ao consumidor em cada etapa da cadeia. $\mathrm{O}$ nível de serviço se destaca como fator de diferenciação frente a esse mercado competitivo. Desse modo, faz-se necessário questionar: como uma empresa do ramo de bebidas localizada na cidade de Juazeiro do Norte - Ceará gerencia o nível de serviços logísticos nas entregas de mercadorias prestadas aos distribuidores?

A logística, segundo Novaes (2004), deve se adaptar a todo esse dinamismo que existe no contexto atual do mercado, já que esse processo tem um papel de grande relevância no processo de garantir a posse do produto por parte do consumidor, podendo ajudar positivamente quando as operações logísticas são bem administradas e esse produto consegue chegar ao cliente em tempo hábil, como também pode ter um reflexo negativo para a empresa prestadora do serviço quando existe uma má administração ou alguma falha nos processos que desencadeiam efeitos negativos na relação entre empresa e clientes.

Para que possa ser eliminado o possível aparecimento desses reflexos negativos, a logística atual deve eliminar de todos os processos tudo aquilo que possa prejudicar os clientes e que não agregue valor, ou seja, tudo aquilo que acarrete somente custos ou perda de tempo, para isso é necessário buscar soluções que sejam eficientes para otimizar os custos e que facilite a satisfação destes. Tendo em vista esse contexto, buscou-se com essa pesquisa verificar como é gerenciado o nível de serviço logístico nas entregas de mercadorias de uma empresa de bebidas localizada na cidade de Juazeiro do Norte-CE. E para o alcance desse resultado, fez-se necessário compreender o que é nível de serviço logístico; verificar como se determina nível de serviço em logística; conhecer ferramentas métricas e indicadores de desempenho logístico, bem como identificar como é determinado o nível de serviço logístico na organização em estudo.

Para os docentes e discentes o estudo servirá como fonte de pesquisa, enriquecendo o conhecimento associado ao ensino e à extensão, deve conduzir e respaldar a sua relação com a 
sociedade que, cada vez mais, busca respostas ágeis, efetivas e consequentes, e ainda fazer com que o aluno adquira um pouco mais de experiência dentro de sua área de atuação, visto que as pesquisas ajudam no contato com a profissão e com a academia.

Tendo em vista os objetivos traçados, optou-se como método de investigação por um levantamento bibliográfico inicial, tendo em vista o conhecimento das teorias já exploradas na literatura disponível, logo após realizou-se um estudo de caso abordando uma empresa de bebidas localizada na cidade de Juazeiro do Norte-CE.

\section{Evolução da Logística}

Segundo Razzolini Filho (2011) com a evolução humana e suas necessidades e desejos a serem satisfeitos, as organizações tem o dever de disponibilizar os seus produtos, como menor custo possível, no momento e local certo onde seus clientes possam consumir os produtos da forma que melhor lhe atenda. O primeiro conceito de logística foi utilizado na década de 40 por militares americanos na segunda guerra mundial e tratava de coordenar todo o processo de aquisição e fornecimento de materiais durante a guerra (CHING, 2009, p. 15). No cenário atual, de acordo com Ballou (2010, p.27) "a logística pode ser definida como o processo de planejamento, implementação e controle do fluxo eficiente e eficaz de mercadorias, serviços e das informações relativas desde o ponto de origem até o ponto de consumo com o propósito de atender às exigências dos clientes".

Anteriormente a logística era vista apenas como uma atividade de apoio e não como uma área estratégica das empresas. Com o passar dos anos, esta foi se tornando cada vez mais complexa. Novaes (2004) destaca que o processo de evolução da logística pode ser dividido em quatro fases, a primeira fase trata-se da atuação segmentada da logística, onde o estoque era o elemento chave na cadeia de suprimentos, já que não havia sistema de informação que auxiliasse no controle da disponibilidade dos produtos, tendo em vista que a maioria dos processos era registrada manualmente.

A segunda e terceira fase da evolução logística conforme o mesmo autor trata-se da integração rígida e da integração flexível. A integração rígida trouxe um aumento acentuado na variação dos produtos, com mais cores e modernização, em contrapartida essas variações trouxeram um aumento nos custos de mão- de- obra, com isso as organizações necessitaram utilizar a multimodalidade no transporte como alternativa de escoamento dos fluxos logísticos. 
A segunda fase tem uma relação estreita com a terceira, já que essa pode ser caracterizada pela integração flexível e dinâmica entre a inter-relação da empresa com seus clientes e seus fornecedores levando em consideração os agentes da cadeia de suprimentos.

$\mathrm{Na}$ quarta fase da logística, ainda conforme o autor citado anteriormente ocorre um salto qualitativo da maior importância nesse processo, onde as empresas de cadeia de suprimentos passaram a mudar a forma de ver e tratar tal processo como uma questão estratégica, ou seja, buscando aperfeiçoar pontualmente as operações e focalizando seus procedimentos, reduzindo os geradores de custos em cada etapa.

Todas essas mudanças constantes na evolução dos processos logísticos se deram a partir das exigências do mercado e das necessidades dos clientes que foram aumentando com o passar do tempo. Oliveira (2011) acrescenta que a logística atualmente ocupa um lugar de destaque na administração moderna e que pode ser atribuído a ela a responsabilidade do sucesso ou insucesso de muitas organizações, pois a logística moderna tratada de forma estratégica utilizase de operações eficientes que viabilizam as empresas a tornarem-se competitivas no cenário atual de mercado, onde existe um elevado número de concorrentes e um número grandioso de custos associados a todas as etapas da cadeia.

O grande desafio dessa gestão está voltado para flexibilidade e minimização dos custos agregados a todas as movimentações, pois, como traz o autor supracitado, a logística passa por uma evolução constante e as empresas deve acompanhar toda essa mudança, buscando soluções que facilitem o alcance de resultados, a redução dos custos, do tempo e a satisfação dos clientes que deve ser o resultado final de todo esse processo.

\section{Atividades Logísticas}

A Logística exerce a função de responder por toda a movimentação de materiais, no ambiente interno e externo da empresa, iniciando pela chegada da matéria-prima até a entrega do produto final ao cliente e muitas vezes, o fluxo reverso.

De acordo com Avozani e Santos (2010) a logística é composta de atividades primárias sendo elas, transporte, manutenção de estoques e processamento de pedidos, as quais possuem fundamental importância na redução de custos e maximização do nível de serviços. As atividades como armazenagem, manuseio de materiais, embalagem, suprimentos, e 
planejamento podem ser consideradas atividades de apoio, que viabilizam um bom desempenho das atividades primárias.

Segundo o Portal Educação (2013) todas as atividades da cadeia de suprimentos sendo elas consideradas primárias são primordiais para atingir os objetivos logísticos que é a redução razoável dos custos e aumento do nível de serviços no transporte, buscando a utilização do modal mais adequado para a movimentação dos produtos, já que essa atividade absorve de um a dois terços dos custos logísticos.

As atividades secundárias exercem função de apoio à atividade primária na obtenção dos níveis de bens e serviços requisitados pelos clientes.

As atividades primárias são compostas por três processos que se pode considerar de grande relevância, que são: transporte, manutenção de estoques e processamento de pedidos. Meirim (2012) traz a relação de junção dessas atividades como a forma de um ciclo crítico da logística e que por esse motivo deve-se ter uma atenção maior com essas, buscando equilíbrio entre o nível de serviço prestado aos clientes e os custos logísticos.

Dentre as atividades primárias está a atividades de transporte que segundo Amorim (2014) é responsável pela movimentação e deslocamento dos fluxos físicos de bens ou serviços ao longo dos canais de distribuição, a logística tem um papel relevante no que se refere à gestão desses transportes, já que esses absorvem expressivos percentuais de custos logísticos.

A gestão eficiente da logística em relação a essas atividades garante resultados mais satisfatórios em relação ao nível de serviço, uma vez que para que haja uma redução significativa de custos, esse estando associado às atividades, ao tempo e a distância, deve existir uma avaliação de todos esses processos ainda nas fases iniciais, para que assim ao final de todo o processo os resultados sejam positivos.

De acordo com Bowersox, Closs (2007) a gestão da cadeia no que se refere ao transporte deve considerar três aspectos que são imprescindíveis em relação à diminuição dos custos e o bom desempenho dos transportes. O primeiro fator que deve ser considerado é o custo associado a essa movimentação, o segundo fator é a velocidade do transporte, que é o tempo necessário para completar uma movimentação específica e o terceiro fator que deve ser considerado é a consistência, que se refere, às variações do tempo necessárias para realizar uma movimentação específica.

É por meio da gestão adequada das atividades primárias com as atividades de suporte e a escolha de modais de transporte adequados que a logística empresarial consegue atender o objetivo de proporcionar aos clientes produtos e serviços que satisfaçam suas necessidades. 


\section{Distribuição física}

Para que a logística desenvolva suas atividades que fazem parte de todo processo da cadeia, desde o processo de aquisição até a entrega dos produtos ou serviços ao consumidor final, deve passar por diversas fases até chegar ao cliente, e para que toda essa sistematização ocorra de maneira eficiente devem ser adotados sistemas de distribuição que se utilizam de diversos modais de transportes que devem se adequar as características e necessidades de cada produto, levando em consideração o tempo, a distância e o custo que será associado a essa distribuição.

Portal Educação (2013) coloca que a distribuição física é o ramo da logística empresarial que trata da movimentação, estocagem e processamento de pedidos de todos os produtos finais. O grande desafio do profissional de logística é o de garantir a entrega desse produto em tempo hábil e a um custo razoável.

Anteriormente, segundo Dias (2010) a distribuição era considerada apenas como um processo que gerava somente custos e que reduzia a lucratividade, já que essa atividade pode ser considerada uma das que mais possui custos associados, com o tempo foi visto que essa atividade era extremamente relevante no que diz respeito ao cumprimento da missão da logística de dispor o produto certo, no local certo e nas condições desejadas pelo cliente.

Com isso a distribuição física pode ser conceituada também de maneira mais abrangente conforme Dias (2010, p. 463) como a "utilização de canais existentes de distribuição e facilidades operacionais, com a finalidade de maximizar a sua contribuição para a lucratividade da empresa, por intermédio de um equilíbrio entre as necessidades de atendimento ao cliente e o custo incorrido".

A distribuição física ou logística como também pode ser chamada, possui uma relação estreita com as demais etapas do processo de distribuição do produto final, e toda e qualquer escolha ou decisão tomada afeta direta ou indiretamente todas as outras áreas. Dias (2010), ainda enfatiza que a distribuição física deve ser estabelecida e formulada com o objetivo de manter uma distribuição adequada de todos os produtos, objetivando o menor custo operacional possível analisando qual o tipo de produto que será entregue, para observar considerado o método de distribuição mais adequado para aquele produto.

Dessa forma, a empresa deve se organizar e avaliar quais métodos de distribuição atenderá as necessidades da empresa e o alcance desse objetivo. 


\section{Nível de Serviço Logístico}

Segundo Bowersox, Closs (2010), em princípio, qualquer organização é capaz de alcançar qualquer nível de serviço logístico se a mesma estiver disposta a alocar os recursos necessários. Na busca por novos clientes e a manutenção dos mesmos a empresa vem investindo bastante e o nível de serviço logístico está sendo um diferencial no atual mercado competitivo. Cada empresa tem sua forma de estipular um nível de serviço. Segundo Ballou (1993), defende que cada empresa deve determinar como será avaliado seu nível de serviço. Por exemplo, o tempo necessário para entrega de pedidos aos clientes, ou a disponibilidade de produtos em estoque.

"Para se oferecer um nível de serviço ao cliente que seja satisfatório, ou que supere suas expectativas, é necessário examinar cuidadosamente os clientes existentes no mercado e na carteira de clientes da empresa" (RAZZOLINI FILHO, 2011, p.42). O serviço ao cliente é um dos componentes que diferencia a logística moderna da abordagem tradicional, já que atualmente a importância não reside somente na busca pela eficiência operacional, mas também pelo o atendimento das necessidades dos clientes (FLEURY, WANKE E FIGUEIREDO, 2000). E aos poucos as organizações vêm se adaptando a logística, para (BOWERSOX, CLOSS E COOPER, 2007). É impossível conseguir praticamente qualquer nível de serviço logístico se uma empresa não estiver disposta a empenhar os recursos necessários.

Desde a produção até a chegada ao consumidor final, as empresas precisam ter o produto ou serviço disponível diferenciado dos concorrentes de boa qualidade preço acessivo estar ao alcance do cliente no momento em que é solicitada, a organização deve fazer o planejamento do modal de transporte mais adequado para a entrega do produto levando em conta o menor custo benefício.

A criação e desempenho logístico básicos são medidos em termos de disponibilidade, desempenho operacional e confiabilidade do serviço (BOWERSOX, COSS E COOPER, 2007). A disponibilidade é dispor de estoque para atender as necessidades dos clientes, O desempenho operacional é o tempo que a empresa leva para fazer a entrega do produto, ou seja, rapidez e eficiência na entrega a confiabilidade do serviço está relacionado a qualidade da logística que medido através do desempenho logístico. 


\section{Indicadores de Nível de Serviço (KPI’s)}

KPI o Indicador-chave de desempenho (Key Performance Indicador), mede o nível de desempenho do processo, focando no "como" e indicando quão bem os processos de tecnologia da informação permitem que o objetivo seja alcançado (SILVA, 2012).

Os indicadores de desempenho, chamados de KPIs, são métricas que quantificam sua performance de acordo com seus objetivos organizacionais (ENDEAVOR BRASIL, 2015).

Para que os indicadores de desempenho tenham resultados significativos dentro da organização, é necessário entender todo o planejamento estratégico e ter objetivos claros no momento de definir as metas que devem ser alcançadas. A partir daí os indicadores de desempenho podem ser direcionados para o monitoramento com os resultados alcançados servem para o processo de tomada de decisão e para as estratégias de melhorias, (ENDEAVOR BRASIL, 2015.)

Os indicadores de desempenho são únicos para cada empresa, pois devem refletir a estratégia da mesma. Assim, na área de logística, para algumas empresas um indicador importante será relacionado ao tempo, enquanto para outras será o custo ou a qualidade. (COELHO, 2011)

De acordo com Bowersox, Closs e Cooper (2007 apud SHIRO, 2011) um sistema de indicadores deve auxiliar na medição e controle do desempenho, e apontar a melhor direção para melhoria do desempenho da operação.

Sink (1985 apud SHIRO, 2011) cita que a medição é uma parte natural das atividades de analisar, controlar, desenvolver e gerenciar processos.

\section{Indicadores de desempenho para o processamento de pedidos e atendimento ao cliente}

Para Bowersox, Closs (2010) a qualidade da logística é fazer tudo de maneira correta, o atendimento de pedido exige a capacidade da prestação de serviço ao cliente, nos termos de disponibilidade e desempenho operacional, para que possa atingir as metas de serviço desejado. $\mathrm{O}$ atendimento do pedido ao cliente deve ser completo, em todos os aspectos do serviço desde recebimento do pedido até a entrega de mercadorias incluindo o faturamento sem erros.

Coelho (2011) relata que o atendimento ao cliente e essencial. Que para as organizações não é uma questão de marketing e sim de sobrevivência. O mesmo ainda acrescenta que o 
mercado está cada vez mais competitivo e se a empresa não tratar bem os seus clientes os concorrentes o farão.

O mesmo autor menciona que para garantir um bom atendimento ao cliente e como anda o processamento de pedidos é necessário acompanhar de maneira simples e eficaz. $\mathrm{O}$ autor ainda menciona que uma forma para fazer esse acompanhamento é através dos indicadores de desempenho, os mesmos permitem ter métricas quantificáveis e comparáveis para avaliar se o processo tem melhorado ao longo do tempo.

O mesmo autor citou alguns indicadores de desempenho para a área de processamento de pedidos e atendimento aos clientes. Assim você terá medidas numéricas para avaliar o desempenho de sua organização:

Entregas no prazo: este é só o primeiro passo para atender o cliente, ou seja, cumprir a data que prometeu. Assim, este indicador medirá o percentual de entregas que foram realizadas no prazo. Deve ser calculado como o percentual de entregas realizadas no prazo dividido pelo total de entregas realizadas (por período, como um mês, por exemplo).

Taxa de atendimento do pedido: não basta entregar no prazo, o produto solicitado deve ser entregue na quantidade correta e no local apropriado, deve atender as especificações do pedido do cliente.

Atendimento e entregas corretas, ou OTIF (On Time, In Full): este é um dos indicadores mais utilizados; o mesmo mede o percentual de pedidos atendidos nas especificações e entregues no prazo correto.

Tempo de ciclo: mede o tempo que se passou desde que o pedido foi recebido (desde que o cliente solicitou os produtos) é calculado a data da entrega menos a data do pedido.

Precisão dos pedidos: mede as devoluções das entregas realizadas. É calculado o total devolvido (em unidades do produto ou em $\mathrm{R} \$$ ) sobre o total enviado tanto em unidades como em monetário. Estes são apenas alguns exemplos de indicadores de desempenho para processamento de pedidos e atendimento aos clientes (COELHO, 2011).

\section{Nível de serviço de entregas de mercadorias}

Esse indicador da área de logística revela os dados de uma das operações mais complicadas e, ao mesmo tempo, mais observadas pelos clientes: a entrega dos produtos. Esse KPI é importante não só para entender como está o desempenho da sua operação de transporte, 
mas também se a sua cadeia de suprimentos funciona de forma eficiente. Serve ainda como base para avaliar o desempenho dos seus fornecedores. Isso é importante para avaliar o grau de confiabilidade de cada um deles com relação a suas entregas e o cumprimento de prazos (ENDEAVOR BRASIL, 2015).

Razzolini Filho (2011) relata que uma organização que valoriza os seus clientes ela busca um diferencial para conseguir um bom nível de serviço logístico. Esse diferencial seria disponibiliza os produtos certos, no tempo certo e hora certa o autor ainda acrescenta que transportes, disponibilidades de estoques, ajudariam em um processamento de pedidos mais rápidos e menor perda de danos de transporte isso afeta geralmente o cliente.

$\mathrm{O}$ quadro a baixo indica o resultado de algumas pesquisas sobre os indicadores de desempenho mais utilizados na logística.

Quadro 1: Indicadores Logísticos mais comuns

\begin{tabular}{|l|c|c|}
\hline \multicolumn{1}{|c|}{ INDICADOR } & $\begin{array}{c}\text { \% DE CLIENTES QUE } \\
\text { USAM O INDICADOR }\end{array}$ & $\begin{array}{c}\text { \% DE CLIENTES QUE } \\
\text { O RECONHECEM } \\
\text { COMO MUITO } \\
\text { IMPORTANTE }\end{array}$ \\
\hline Entregas 100\% no prazo & 86 & 91 \\
\hline Preenchimento 100\% nas ordens de venda & 75 & 88 \\
\hline $\begin{array}{l}\text { Acuracidade das Faturas (faturas sem } \\
\text { erros) }\end{array}$ & 69 & 77 \\
\hline $\begin{array}{l}\text { Performance no cumprimento dos prazos } \\
\text { de entrega }\end{array}$ & 66 & 82 \\
\hline Tempo de atendimento da ordem de venda & 63 & 78 \\
\hline $\begin{array}{l}\text { Excessos de Estoque / Pedidos pendentes } \\
\text { (falta de estoque) }\end{array}$ & 62 & 73 \\
\hline $\begin{array}{l}\text { Quantidades entregues a mais ou a menos } \\
\text { /Danos nas entregas }\end{array}$ & 61 & 84 \\
\hline Itens de ordens de venda 100\% atendidos & 55 & 63 \\
\hline Devoluções e Reentregas & 44 & 68 \\
\hline Custo de Frete & 44 & 63 \\
\hline Tempo de resposta a consulta & 36 & 77 \\
\hline Preenchimento de caixas /embalagens & 32 & \\
\hline
\end{tabular}

Fonte: Supply (apud SILVA, 2008)

Entende-se tais fatores como medidores de desempenho do serviço ao cliente, ou, simplesmente, indicadores de nível de serviço que mede os desempenhos utilizados nas estratégias. Para fins deste trabalho, serão entendidos tais fatores como medidores de desempenho do serviço ao cliente, ou simplesmente, indicadores de nível de serviço. 


\section{O Mercado de Bebidas o Brasil}

No Brasil umas das principais produções de bebidas que vem se destacando é a produção de refrigerante, em seguida vem à produção de cerveja. Esse é um dos setores responsáveis pela geração de milhares de postos de empregos em todo o país. Em relação ou comercio exterior, cerveja e refrigerante mostram baixíssima penetração de importação, segundo Cervieri Júnior et al. (2016)

Silva (2012) destaca que o setor de bebidas envolve vários fatores, os mais importantes são: concorrência, diferenciação, qualidade e crescimento. $\mathrm{O}$ mesmo autor menciona que no Brasil o setor de bebidas é regulamentado pela ANVISA (Agencia Nacional de Vigilância Sanitária), onde ele coordena, supervisiona e controlam as atividades, informações, inspeção de qualidade, controle de riscos e estabelece normas e padrões. Ele ainda destaca que a indústria de bebidas no Brasil tem grande participação no PIB nacional chegando a 7,5\% de participação, só o segmento de cerveja contribui com $1,5 \%$ de participação e ainda destaca que o setor de bebidas é de forte expressão na economia brasileira e é constituído por vários produtos, são divididos em: águas envasada, Bebidas não alcoólicas industrializadas, Bebidas alcoólicas e Bebidas tradicionais.

\section{Metodologia da Pesquisa}

O procedimento metodológico utilizado nesta pesquisa foi um estudo de caso onde foi analisado o nível de serviço logístico da organização. No que se refere à caracterização da pesquisa, o estudo é qualitativo de caráter exploratório-descritivo, com pesquisa bibliográfica e coleta de dados. Descritiva, porque os dados são observados, registrados, analisados. Segundo Gil (2010) as pesquisas que são realizadas com objetivos profissionais todas se enquadram nesta categoria. E exploratória por que proporciona maiores informações sobre o assunto a ser analisado. Segundo Gil (2010) as pesquisas exploratórias proporcionam maior familiaridade com o problema, o mesmo relata que a coleta de dados pode ocorrer de várias maneiras, 1 . Levantamento bibliográfico; 2. Entrevistas com pessoas que tenham conhecimento no assunto; e 3. Análises de exemplos que estimulem a compreensão. Severino (2014) aborda que uma pesquisa exploratória é aquela que busca somente informações sobre o determinado objetivo delimitando um campo de trabalho. 
Iniciou-se com uma Pesquisa bibliográfica para um melhor aprofundamento acerca do tema a ser desenvolvido, com o objetivo de conhecer os conceitos e as aplicações relacionadas ao nível de serviço logístico na entrega de mercadorias e quais as ferramentas utilizadas pela empresa para avaliar ou garantir um bom nível de serviço. Severino (2014) relata que uma pesquisa bibliográfica é aquela que se utiliza alguns registros disponíveis como documentos, livros, artigos e teses onde já foram pesquisados por outros autores.

A coleta de dados dessa pesquisa iniciou-se em março de 2016, sendo concluída em maio do referente ano, foi realizada em uma empresa " $X$ " no ramo de bebidas com sede na cidade de Juazeiro do Norte, interior do Ceará. A mesma foi fundada no ano de 1962. Atualmente a sede da empresa conta com uma área de mais de $700.000 \mathrm{~m}^{2}$, e atende ao nordeste do Brasil e parte da região norte. Hoje a mesma conta com cerca de 370 funcionários.

O presente artigo teve como instrumento de coleta de dados uma entrevista realizada com o gestor do setor de logística, em seguida foi aplicado um questionário com um número significativo de distribuidores que são os representantes da empresa em estudo, cuja amostra foi feita por acessibilidade. O questionário foi elaborado pelo pesquisador com questões estruturadas fechadas, onde foi abordado o nível de serviço logístico da organização em estudo. Os dados foram analisados através de gráficos do Microsoft Excel 2010.

\section{Análise e Discussão dos Resultados}

\section{Entrevista com Gestor da Empresa}

A entrevista com o gestor da empresa iniciou-se com a abordagem acerca do seu conhecimento sobre a logística, onde o mesmo destaca que "é otimizar e racionalizar o processo disponibilizando o produto certo, no lugar certo, no momento correto, em sua condição desejada, ao menor custo possível, superando tempo e distancia de forma eficaz e eficiente", esse dado pode ser confirmado por Razzolini Filho (2011) no decorrer deste trabalho.

Ele enfatizou ainda que dentre todas as etapas do processo, a que considerava de maior relevância "é a entrega de mercadoria ao cliente final". A ENDEAVOR BRASIL (2015) menciona que esse é um indicador de desempenho da área da logística mais complicado de gerenciar, visto que esse processo é o que o cliente mais observa. 
O gerenciamento do processo da empresa é feito "estudando viabilidade de melhorias no canal de distribuição, analisando seus setores de suprimento, distribuição e transporte, na busca incessante de um serviço satisfatório ao cliente, procurando agilizar ao máximo a entrega da mercadoria". Essa informação apresentada pelo gestor traz à tona a preocupação em oferecer um bom atendimento aos seus clientes, através do acompanhamento de fatores que podem favorecer a fidelização dos mesmos.

Um outro aspecto relevante foi o uso de tecnologia, onde o entrevistado menciona que "a principal ferramenta é a tecnologia de informação, pois a mesma consiste em ferramentas atualizadas para obter acesso rápido às informações, auxiliando nas análises e nas tomadas de decisões". Fato esse que propicia uma tomada de decisões efetivas no que diz respeito a indicadores esperados pelo público em questão.

No tocante às formas de distribuição física externa, o gestor citou que o modal utilizado para as entregas das mercadorias é o rodoviário, mais precisamente caminhões, acrescentou ainda que "a empresa possui uma frota própria, que atende num raio de $150 \mathrm{~km}$ em torno da fábrica, com o propósito de ofertar serviços adequados aos clientes a um custo aceitável como também preservar a satisfação dos mesmos, porém, atualmente a empresa terceirizou o serviço de distribuição acima de $150 \mathrm{~km}$ da Fábrica, a mesma usou alguns critérios para a escolha da parceria que são: Estrutura física, estrutura logística, planejamento estratégico, entre outros”. Compreendendo que "existe uma ameaça relacionada a esse tipo de atividade, pois eles perdem um pouco do contato direto com o cliente, já que esse serviço é prestado por outra empresa”.

Em seguida foi abordado como é feito o gerenciamento de estoque da organização, onde entrevistado informou que "o controle é a parte prática para o planejamento de estoque. $\mathrm{O}$ gerenciamento é feito em mecanismo de monitoramento através sistema e planilhas: Recebimento da produção; Organização de estoque; Vencimento de produto, onde o primeiro a ser produzido é primeiro que sair para a distribuição", visto que a empresa administra produto em processo e produto acabado, "a matéria prima é toda agregada ao produto acabado, o volume depende da duração da reposição, da frequência de uso e ao investimento".

Seguindo com a entrevista o gestor citou que "o tempo médio de entrega de mercadorias aos clientes na região do Cariri é de 24 horas, com tolerância de 48 horas". Nas demais cidades entregas preestabelecidas de acordo com a distância das mesmas. Esse foi um dos assuntos que o mesmo enfatizou anteriormente que de todas as etapas do processo a que considerava de maior relevância era a entrega de mercadoria ao cliente final. Onde exige uma atenção maior por que 
de todos os níveis de serviço oferecidos esse é o que o cliente mais enxerga. A ENDEAVOR (2015) confirma que esse indicador é um dos mais complicados.

Foi abordado qual é o conceito de indicador de desempenho para o mesmo ele relatou que "indicador de desempenho, é um processo focado em como a tarefa é realizada, medindo seu desempenho e se estão conseguindo atingir os objetivos preestabelecidos". O mesmo citou que "o indicador mais utilizado para o atendimento ao cliente é o de entrega de mercadorias". Mencionou ainda que a organização gerencia o nível de serviço ofertado aos clientes, analisando os dados das operações mais complexas, investigando e implementando soluções, pois um bom nível de serviço traz grandes benefícios para a organização, tais como "Redução de custos; flexibilidade nos processos produtivos e administrativos; agilidade nas entregas; aumento a produtividade; competitividade no mercado entre outros".

Para finalizar, foi observado que o nível de serviço pode ser descrito pela relação do preço, qualidade e serviço, já que existe um grande número de concorrentes, indagou-se se ele considerava que o nível de serviço pode ser avaliado como um diferencial competitivo frente a essa concorrência, onde as vendas podem ser influenciadas pela disponibilidade de estoque, rapidez nos processos de pedidos e de entrega. $\mathrm{O}$ gestor respondeu que "considera sim como um diferencial competitivo e acrescenta ainda que a empresa busca esse diferencial diariamente, procurando repassar aos seus colaboradores a importância de um atendimento de excelência, tendo reuniões semanais para repasse de feedback e informações relevantes".

Dessa forma, conclui-se que um bom nível de serviço impacta diretamente na satisfação dos clientes, assim como o mau gerenciamento dos recursos ou falta de estoque pode trazer impactos negativos e prejudicar as vendas. Com isso faz-se necessário a avaliação constante do desempenho de todas as atividades, desde a chegada do produto por meio do fornecedor até a entrega ao cliente final, prezando pela qualidade em todas as etapas do processo, como pela satisfação plena dos clientes.

\section{Análise dos Distribuidores}

Para verificar se o nível de serviço logístico nas entregas de mercadorias é o mais observado pelos clientes, foi aplicado um questionário com 32 distribuidores do ramo de bebidas na cidade de Juazeiro do Norte - Ceará, os dados a seguir mostram os resultados obtidos. 
Gráfico 1: Frequência com que faz pedidos de Mercadorias

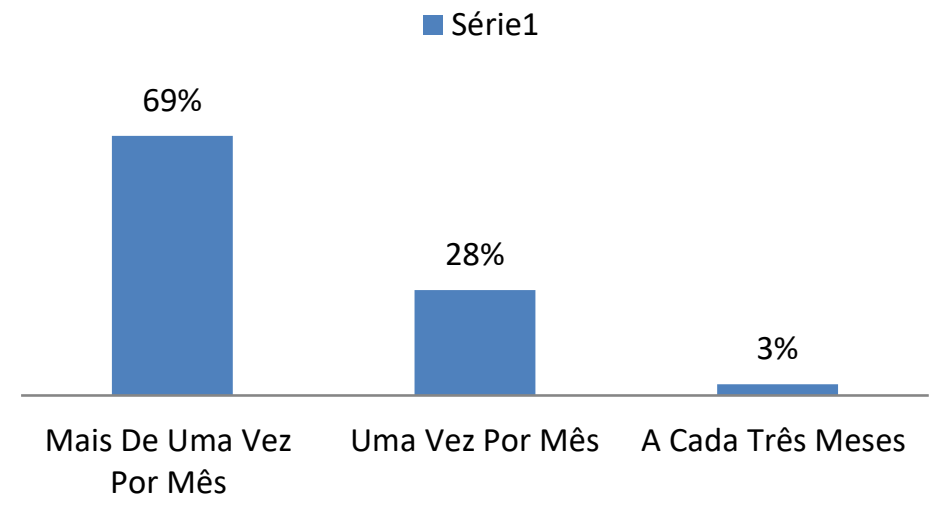

Fonte: Dados da Pesquisa (2016)

Pode-se verificar que $69 \%$ dos distribuidores são clientes fidelizados que compram mais de uma vez por mês, os mesmos são fundamentais para avaliar o nível de serviço logístico da empresa em estudo, detendo bom conhecimento a respeito do processo oferecido pela a organização. Coelho (2011) cita que o processo de pedidos para ser eficaz é necessário o acompanhamento.

Gráfico 2: Formas de realização dos pedidos

- Série1

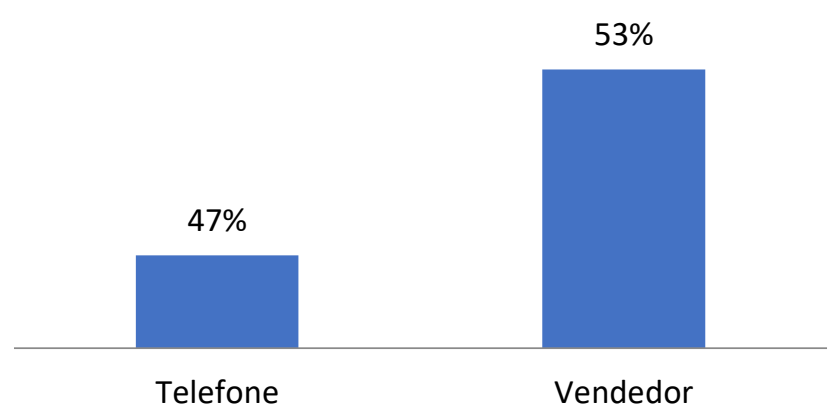

Fonte: Dados da Pesquisa (2016)

Pode-se verificar no gráfico que 53\% dos clientes tem um relacionamento direto com a empresa através do vendedor, meio pelo qual são feitos os pedidos de mercadorias. Já $47 \%$ prefere realizar os pedidos através de telefone. 
Gráfico 3: Percepção do Nível de Serviço Logístico na Entrega de Mercadoria

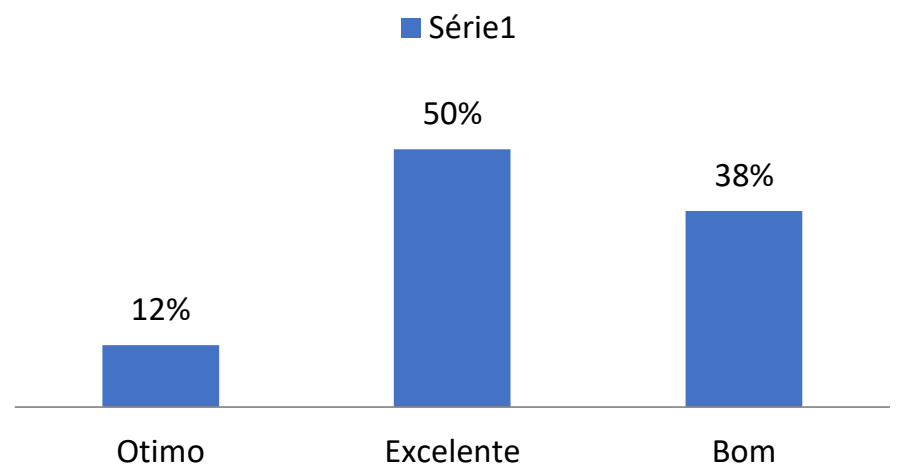

Fonte: Dados da Pesquisa (2016)

Segundo a Endeavor Brasil (2015) esse indicador da área da logística revela os dados de uma das operações mais complicadas e, ao mesmo tempo, é a mais observada pelos clientes. Percebe-se que o nível de serviço na entrega de mercadorias é o mais observado pelos clientes, onde $50 \%$ consideram que o nível de serviço prestado pela a organização e excelente $38 \%$ considera um bom nível de serviço e $12 \%$ considera ótimo.

Gráfico 4: Entrega 100\% no Prazo

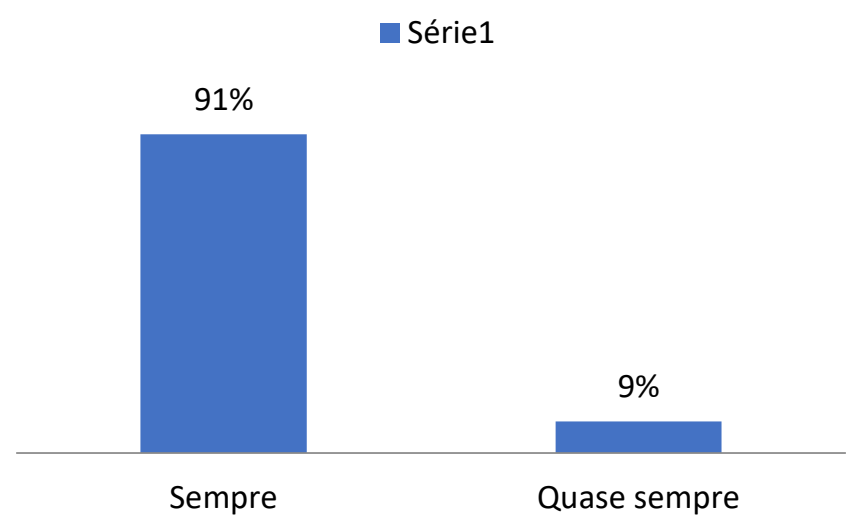

Fonte: Dados da Pesquisa (2016)

De acordo com o resultado, o gráfico mostra que a empresa realmente cumpre com o prazo determinado, $91 \%$ dos clientes afirmam. Porém, $9 \%$ afirmam que a organização não consegue cumprir com o prazo. Razzolini Filho (2011) cita que as organizações que valorizam seus clientes, buscam um diferencial atendendo os desejos e as necessidades dos mesmos. 
Gráfico 5: Os Produtos Chegam 100\% Com Qualidade

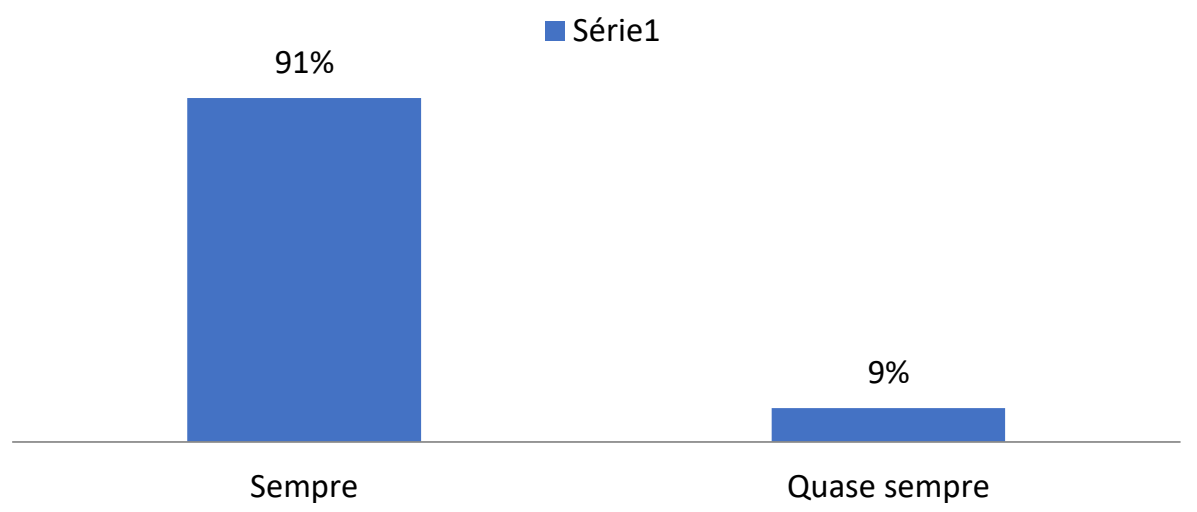

Fonte: Dados da Pesquisa (2016)

O gráfico 5 mostra que $91 \%$ dos clientes afirmam que a empresa consegue entregar todos os produtos com qualidade sem nenhum dano, enquanto $9 \%$ confirma que os produtos quase sempre existem alguns problemas. Visto que o indicador em questão é aquele que a empresa utiliza como parâmetro de destaque, observa-se a necessidade de um melhor acompanhamento a esses distribuidores.

Gráfico 6: Substituição dos Produtos Danificados

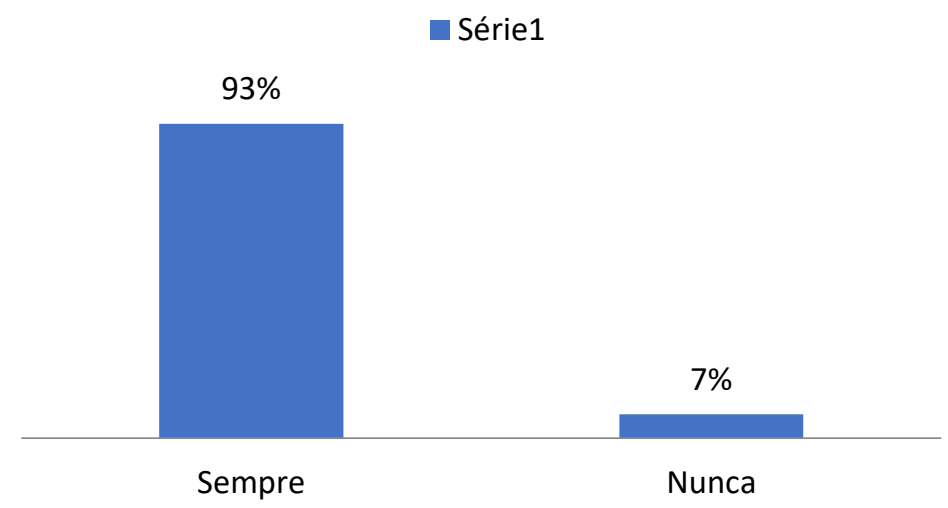

Fonte: Dados da Pesquisa (2016)

O gráfico 6 apresenta a satisfação do cliente quanto ao serviço prestado pela empresa, destacando que $93 \%$ deles afirmam que quando existe algum produto com defeito a organização faz a substituição sem nenhum problema, embora $7 \%$ não considerem eficácia nesse serviço. 
Gráfico 7: Contato da Empresa a respeito das condições de recebimento da mercadoria

Série1

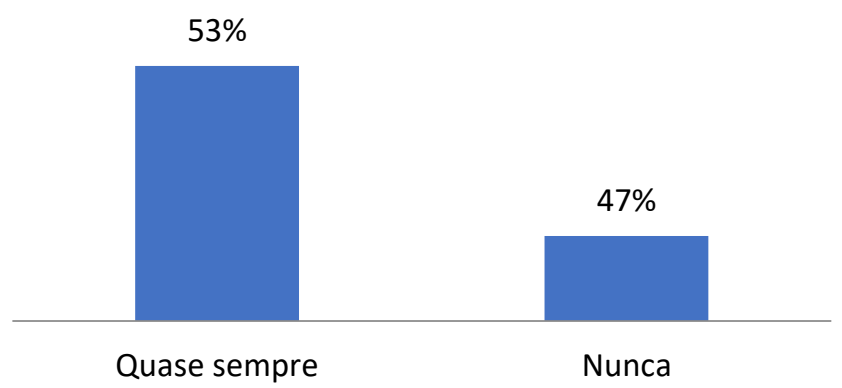

Fonte: Dados da Pesquisa (2016)

53\% dos entrevistados afirmaram que a organização quase sempre entra em contato para saber ser a mercadoria chegou sem danos, porém percebe-se uma divergência ao se verificar o alto percentual (47\%) que confirmaram que a empresa nunca entra em contato para se informar como a mercadoria chegou. No tocante ao indicador "distribuição física", esse fato é significativo e requer uma análise detalhada para reestruturação da atividade em questão.

Gráfico 8: Reclamações por atraso ou produtos danificados

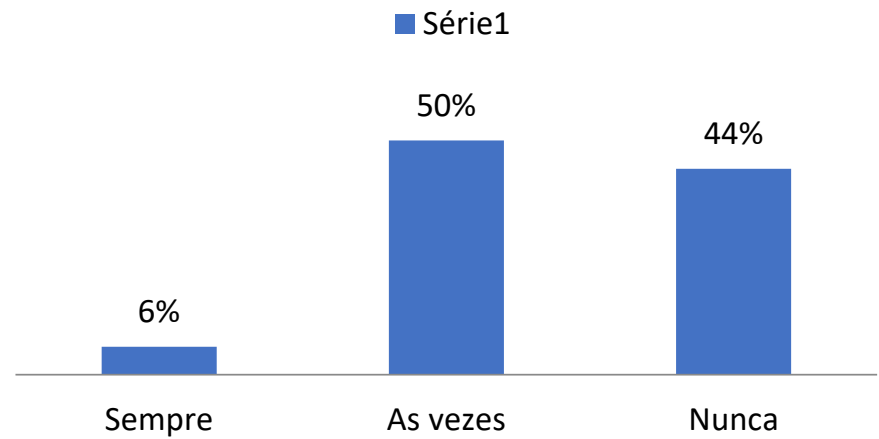

Fonte: Dados da Pesquisa (2016)

Pode-se observar no gráfico 8 que $6 \%$ dos entrevistados mencionaram que sempre fazem reclamações por algum tipo de atraso ou "dano". No entanto $50 \%$ as vezes fazem reclamações e $44 \%$ nunca fizeram nenhum tipo de reclamações. 


\section{Gráfico 9: Produtos Disponíveis}

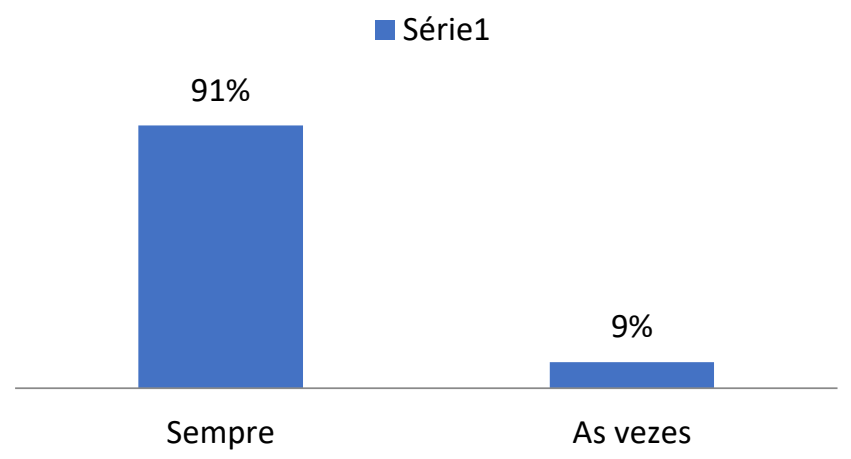

Fonte: Dados da Pesquisa (2016)

No que tange a disponibilidade de produtos frente às necessidades dos clientes, o gráfico 9 destaca esse aspecto visto que $91 \%$ dos distribuidores afirmam que sempre tem produtos disponíveis, enquanto apenas $9 \%$ afirmam que às vezes a empresa não tem os produtos disponíveis.

\section{Gráfico 10: Atendimento ao Cliente}

- Série1

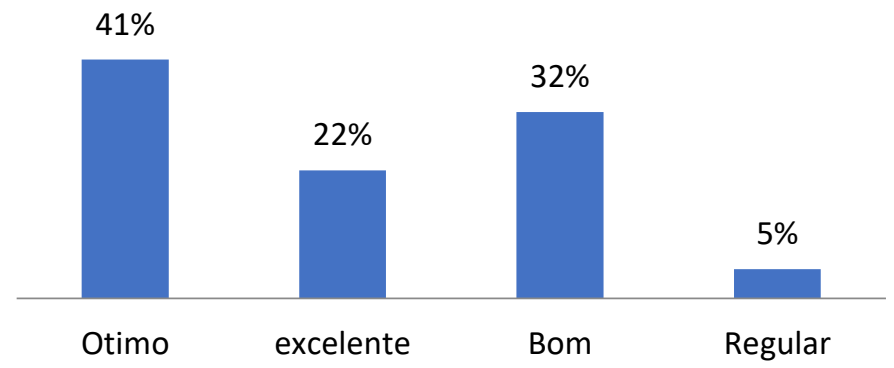

Fonte: Dados da Pesquisa (2016)

O gráfico 10 apresenta a percepção dos distribuidores no tocante ao atendimento. Observa-se uma satisfação, visto que a maioria (41\% ótimo, $22 \%$ excelente, $32 \%$ bom) enquanto 5\% dos entrevistados consideram regular. Coelho (2011) relata que atendimento ao cliente é essencial e que o mercado está cada vez mais competitivo é se você não tratar bem os seus clientes os concorrentes farão. 


\section{Gráfico 11: Excelência em Nível de Serviço}

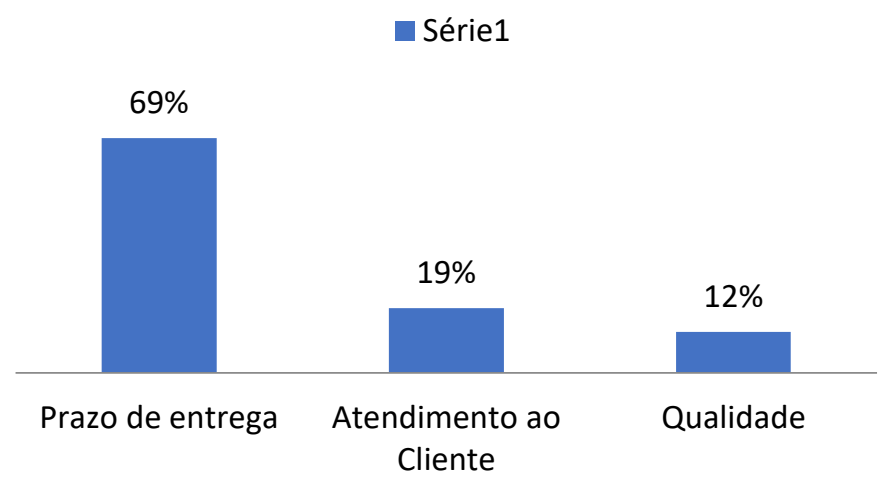

Fonte: Dados da Pesquisa (2016)

O gráfico mostra a percepção dos entrevistados a respeito em excelência em nível de serviço, 69\% dos entrevistados confirmam que o prazo de entrega é considerado como prioridade em excelência, já 19\% considera o atendimento ao cliente e 12\% afirmam que é qualidade. Como já foi abordado na pesquisa o gráfico novamente traz resultados onde o nível de serviço na entrega é o mais observado pelos clientes.

\section{Considerações Finais}

Tendo em vista os objetivos traçados para a realização desse estudo, observou-se que a empresa não apenas compreende a importância de um serviço logístico adequado, como traça medidas que favoreçam uma percepção do cliente no tocante aos indicadores por ela destacados. A distribuição física é o indicador que se destaca no planejamento da empresa, porém ainda se percebe a necessidade de cuidados para a efetividade do mesmo.

De acordo com os resultados obtidos na pesquisa com o gestor, obteve-se que a empresa busca continuamente a melhoria de seus serviços, determinando fatores que favoreçam o melhor desempenho no atendimento às necessidades de seus clientes desde o atendimento no processamento de pedidos até a entrega dos produtos. Os distribuidores, em sua maioria, percebem com clareza o desempenho da empresa no que diz respeito aos indicadores de serviço logístico ofertados.

Ao final desse estudo, pode-se afirmar a importância de um serviço logístico satisfatório, tendo em vista indicadores adequados ao público a ser atendido. É de grande 
relevância à empresa planejar as suas atividades tendo em vista a satisfação do consumidor, favorecendo assim a sua manutenção no mercado competitivo da atualidade.

Para pesquisas posteriores sugere-se uma comparação do desempenho desses indicadores no tocante à cadeia de suprimentos que envolve o caso em questão, selecionando fornecedores, distribuidores e consumidor final para a análise, identificando assim gargalos que interferem a excelência do processo.

\section{Referências}

AMORIM, Luan Ferreira de. A importância dos sistemas de transportes, 2014. Disponível em: <http://www.administradores.com.br/artigos/academico/a-importancia-dos-sistemas-detransportes/78238/>. Acesso em: 18 nov. 2015.

AVOZANI Camila; SANTOS, Aline Regina. Logística empresarial - conceitos e definições, 2010.Disponível em: <http://www.logisticadescomplicada.com/logistica-empresarialconceitos-e-definicoes>. Acesso em: 15 nov. 2015.

BALLOU, Ronald H. Gerenciamento da cadeia de suprimentos/Logística empresarial, 5 ed. Porto Alegre: Bookman, 2010.

BALLOU, Ronald H. Logística empresarial: transporte, administração de matérias e distribuição física. São Paulo: Atlas, 1993.

BOWERSOX, Donald; CLOSS, David J.; COOPER, M. Bixby. Gestão da cadeia de suprimentos e logística. 1 ed. Rio de Janeiro: Elsevier, 2007.

BOWERSOX, Donald; CLOSS, David J. Logística empresarial: o processo de integração da cadeia de suprimento. 1.ed. São Paulo: Atlas, 2010.

COELHO, Leandro. Indicador de desempenho logístico (kpis). 2011. Disponível em:

<http://www.logisticadescomplicada.com/indicadores-de-desempenho-kpi/>. Acesso em: 15 nov. 2015

CHING, Hong Yuh. Gestão de estoques na cadeia de logística integrada: Supply Chain. São Paulo: Atlas, 1999.

CERVIERI JÚNIOR, Osmar et al. $O$ setor de bebidas no Brasil. <http:/www.bndes.gov..br/bibliotecadigital>. Acesso em: 20 abril 2016.

DIAS, Marco Aurélio P. Administração de materiais: uma abordagem logística. 5.ed. São Paulo: Atlas, 2010.

ENDEAVOR BRASIL. 5 indicadores de desempenho para medir seu sucesso, 2015. 
Disponivel em:<Endeavor @ https://endeavor.org.br/indicadores-de-desempenho/>. Acesso em: 25 nov. 2015.

FLEURY, F. P.; Wanke, P.; Figueiredo, K. F. (Org.) Logística Empresarial: a perspectiva brasileira. São Paulo: Editora Atlas, 2000.

GIL, Antônio Carlos. Como elaborar projetos de pesquisa. 5. Ed. São Paulo: Atlas, 2010.

MEIRIM, Hélio. As atividades de apoio da logística, 2012. Disponível em: <http://www.administradores.com.br/artigos/tecnologia/as-atividades-de-apoio-dalogistica/65970/>. Acesso em: 15 nov. 2015.

NOVAES, Antônio Galvão. Logística e gerenciamento da cadeia de distribuição: estratégia, operação e avaliação. 2. ed. Rio de Janeiro: Elsevier, 2004.

OLIVEIRA, Francisco Marcio Ferreira de. A Evolução da Logística. 2011. Disponível em: <http://www.administradores.com.br/artigos/marketing/a-evoluçao-da-logística/53747/>.

Acesso em: 15 nov. 2015.

Portal Educação. Distribuição física: logística empresarial. 2013. Disponível em: <http://www.portaleducacao.com.br/educacao/artigos/31564/distribuicao-fisica-logisticaempresarial>. Acesso em: 15 nov. 2015.

Portal Educação. Logística empresarial e as atividades primárias e de apoio. Disponível em: $<$ http://www.portaleducacao.com.br/educacao/artigos/31365/logistica-empresarial-eaatividades-primarias-e-de>. Acesso em: 16 nov. 2015.

RAZZOLINI FILHO, Edelvino. Logística e evolução na administração desempenho e flexibilidade. 1. ed. Curitiba: Juruá, 2011.

SHIRO, Luiz Henrique. Implantação de um sistema de indicadores de desempenho para a operação logística de uma empresa de comércio eletrônico. São Paulo, 2011. Disponível em: $<$ http://pro.poli.usp.br/wp-content/uploads/2012/pubs/implantacao-de-um-sistema-deindicadores-de-desempenho-para-a-operacao-logistica-de-uma-empresa-de-comercioeletronico>. Acesso em: 15 nov. 205.

SEVERINO, Antônio. Metodologia do trabalho científico. 23 $23^{\mathrm{a}}$ ed. São Paulo: Cortez, 2014. Disponível em: <https://www.metodista.br/revistas/revistas-unimep/index.php/cienciatecnolo gia/article/viewFile/998/678>. Acesso em: 16 nov. 2015.

SILVA, Aldo. KPI Nível de Serviço. 2012. Disponível em: <http://www.administradores. com.br/artigos/tecnologia/kpi-nivel-de-servico/64919/. Acesso em: 16 nov. 2015.

SILVA, Fabio. Análise Setorial, Análise quantitativa do setor de bebidas no período de 2008 a 2010. 2012. Disponível em: <http://www.administradores.com.br /artigos/marketing/analise-setorial-analise-quantitativa-do-setor-de-bebidas-no-periodo-de2008-a-2010/67913/>. Acesso em: 19 abr. 2016. 
SILVA, Liliane. Nível de serviço logístico: estudo de caso em uma empresa de bebidas da Paraíba. 2008. Disponível em: http://www.produçao.ufrga.br/arquivos/disciplinas/495 p20090334 enegep nível de serviço logístico.pdf. Acesso em: 19 abr. 2016.

\section{Como citar este artigo (Formato ABNT):}

SILVA, Vicente Jacó Alves da; OLIVEIRA, Alyne Leite de. Análise do Nível de Serviço Logístico nas Entregas de Mercadorias em Uma Empresa de Bebidas na Cidade de Juazeiro do Norte-CE. Id on Line Rev.Mult. Psic., 2019, vol.13, n.43, p. 761-783. ISSN: 1981-1179.

Recebido: 07/12/2018;

Aceito: 08/12/2018 